\title{
Early Bilirubin Levels Following Percutaneous Biliary Drainage and Stenting Performed for Malignant Biliary Obstruction
}

\section{Malign Biliyer Tıkanıklıkta Uygulanan Perkütan Biliyer Drenaj ve Stentleme Sonrası Erken Dönemde Bilirubin Seviyeleri}

\author{
Mehmet Burak Çildağ, Ömer Faruk Kutsi Köseoğlu
}

Adnan Menderes Üniversitesi Tıp Fakültesi Radyoloji Bölümü

Dergiye Ulaşma Tarihi: 01.02.2017 Dergiye Kabul Tarihi: 01.03.2017 Doi: 10.5505/aot.2017.82905

\section{ÖZET}

Giriş ve Amaç: Malignitelere ikincil safra yolu tıkanıklığı ve bilirubin yükselmesi görülebilir. Kemoterapi uygulanabilmesi için bilirubin seviyesinin belli bir seviyenin altında olması gereklidir. Safra yolları tıkanıklıklarında perkütan biliyer drenaj ve stentleme palyatif tedavide uygulanmaktadır. Perkütan biliyer drenaj sonrası bilirubin seviyeleri düşmektedir. Bilirubin seviyelerinde belli miktara düşme zamanı ile ilgili çalışmalar mevcuttur. Bu çalışmada biz işlem öncesi seviyesine bakılmadan 2 ay içinde $2 \mathrm{mg} / \mathrm{dl}$ ' nin altına düşen bilirubin seviyesine sahip olgularda işlem sonrası kısa dönemdeki bilirubin seviyesindeki değişimi göstermeyi amaçladık. Yöntem ve Gereçler: Ocak 2014- Aralık 2016 tarihleri arasında malign sebeplere bağlı tıkayıcı sarılık gelişmiş ve PBD uygulanmış ve işlem sonrası 2 ay sonra biluribin seviyesi $2 \mathrm{mg} / \mathrm{dl}$ nin altına düşmüş olguların işlemden bir gün önceki, işlem sonrası 1.,7., ve 15. gündeki bilirubin miktarları kaydedildi. Tüm hastalarda safra tıkanıklığa yol açan tümör çeşidi ve tıkanıklığın seviyesine bakıldı.

Bulgular: Çalışma kriterlerine uyan 40 hasta değerlendirildi. İşlem öncesi ortalama bilirubin seviyesine göre ortalama bilirubin miktarında 1. gün $\% 17,7,7$. gün $\% 38,4$ ve 15 . Gün $\% 59,4$ azalma izlendi. Bilirubin düşme miktarıyla sadece işlem öncesi bilirubin seviyesiyle ilişki mevcuttu $(\mathrm{p}<0.001)$. Tıkanma seviyesi, tıkanma etiyolojisini oluşturan malignite ve karaciğer metastazı olup olmaması ile bilirubin düşüş miktarı arasında ilişki saptanmadi.

Tartışma ve Sonuç: Perkütan biliyer drenaj ve stentleme malign sebeplere bağlı safra yolu tıkanıklığında palyatif tedavide yer almakta olup işlemin amaçlarından biride bilirubin seviyelerini düşürerek hastaya kemoterapi uygulanabilmesine olanak sağlamasıdır. Bu çalışma ile perkütan biliyer drenaj ve stentleme sonrası 2. ayda $2 \mathrm{mg}$ /dl nin altına bilirubin seviyesine inmiş olgularda 1. günde, 7. günde ve 15. günde bilirubin seviyelerindeki ortalama düşüşün sırasıyla \%17,7, \%38,4 ve \% 59,4 olduğu ve işlem öncesi bilirubin seviyesinin erken dönem bilirubin miktarındaki değişiklikle ilişkili olduğu görülmüştür.

Anahtar Kelimeler: Perkütan biliyer drenaj, Bilirubin, Malign biliyer tıkanıklık

\begin{abstract}
Introduction: Secondary bile duct obstruction and bilirubin elevation may be observed in malignancies. Bilirubin levels below a specified amount are required in order to administer chemotherapy. Percutaneous biliary drainage (PBD) and stenting are performed for palliative treatment of bile duct obstructions. Bilirubin levels decrease after percutaneous biliary drainage. In this study, we aimed to demonstrate the postoperative short-term change in bilirubin levels in cases whose bilirubin levels decreased below $2 \mathrm{mg} / \mathrm{dL}$ within 2 months, regardless of predrainage level.

Material and Methods: The amounts of bilirubin on the day before percutaneous biliary drainage, and on post percutaneous biliary drainage days 1,7 and 15 were recorded for technically successful cases who had obstructive jaundice due to malignant causes on dates January 2014-December 2016 for cases whose bilirubin levels decreased to $<2 \mathrm{mg} / \mathrm{dL}$ within 2 months after the procedure. The type and degree of tumor leading to bile obstruction was examined in all patients.

Results: In study period, 40 patients who met the criteria were found. A decrease by $17.7 \%$ on day $1,38.4 \%$ on day 7 and $59.4 \%$ on day 15 was observed in the mean bilirubin amount compared to the pre PBD mean bilirubin level.The amount of bilirubin decrease was only correlated with predrainage bilirubin level. No correlation was found between the amount of bilirubin decrease and the degree of obstruction, the presence or absence of malignancy and liver metastasis that constitutes the etiology of obstruction.
\end{abstract}


Discussion and Conclusion: Percutaneous biliary drainage and stenting is considered as palliative treatment of bile duct obstruction due to malignant causes and purposes of the procedure include decreasing bilirubin levels to enable chemotherapy administration for the patient. For cases whose bilirubin levels had decreased to $<2 \mathrm{mg} / \mathrm{dL}$ at 2 months after percutaneous biliary drainage and stenting, this study demonstrated the mean decrease in bilirubin levels on days 1,7 and 15 as $17.7 \%, 38.4 \%$ and $59.4 \%$, respectively.

Keywords: Percutaneous Biliary Drainage, Bilirubin, Malignant Biliary Obstruction

\section{Giriş}

Safra yollarındaki tıkanıklığa veya basıya bağl1 sarılık, sık olarak karşımıza çıkabilmektedir. Safra yollarında tıkanıklık taş gibi benign durumlarda olabildiği gibi safra yollarına tümoral yayılım veya tümoral bir kitlenin dıştan basısına ikincil de gelişebilir. Periampüller karsinom, kolanjiokarsinom, safra kesesi karsinomu, hepatik hilusda ve hepatoduodenal ligamanda bulunan metastatik lenf nodları, malign sebeplere bağlı gelişen safra yolu tıkanıklığının sık sebepleridir (1). Ana semptom sarılık olmakla beraber bazı hastalarda kolanjit ve sepsis de meydana gelebilir. Malignitelerde sarılık gelişmesi kötü prognozu göstermektedir $(2,3)$ Maligniteli olgularda bazı kemoterapi ajanlarının uygulanabilmesi için normal karaciğer fonksiyonları gereklidir. Yüksek bilirubin seviyelerinde toksisiteye neden olabileceğinden, birçok kemoterapotik ajanın uygulanması kontrendikedir $(4,5,6)$. Perkütan biliyer drenaj (PBD) ve safra yollarına yerleştirilen stentler malign sebeplere bağl1 gelişen sarılığın palyatif tedavisinde önemli yere sahiptir. PBD ve/veya safra yollarına yerleştirilen stentler ile yüksek serum bilirubin seviyeleri düşer ve buna bağlı semptomlar geriler. Ayrıca yüksek serum bilirubin seviyelerinin düşmesi hastaların kemoterapi alabilmesine olanak sağlar. Hastanın kemoterapi alabilmesi için serum bilirubin seviyesinin $2 \mathrm{mg} / \mathrm{dl}$ 'nin altına inmesi genellikle yeterlidir (6). PBD sonrası biluribin seviyesinin $5 \mathrm{mg} / \mathrm{dl}, 2 \mathrm{mg} / \mathrm{dl}$ ve $1 \mathrm{mg} / \mathrm{dl}$ nin altına inme süresiyle ilgili çalışmalar yapılmıştır $(3,7)$. Ancak bu çalışmalarda işlem sonrası kısa dönemde ki bilirubin seviyelerindeki değişiklikler gösterilmemiştir.

Bu çalışmada Ocak 2014- Aralık 2016 tarihleri arasında malignitelere sekonder gelişmiş tıkayıcı sarılığın tedavisinde palyatif amaçla PBD yerleştirilmesi sonrası erken dönemde serum bilirubin miktarındaki düşme miktarının retrospektif olarak değerlendirilmesi amaçlanmıştır.

\section{Gereç ve Yöntem}

Adnan Menderes Üniversitesi etik kurulundan onay alındıktan sonra Ocak 2014- Aralık 2016 tarihleri arasında malign sebeplere bağlı tıkayıcı sarılık gelişmiş ve PBD uygulanmış olguların işlem görüntüleri radyoloji arşiv sisteminden ve işlemden bir gün önceki, işlem sonrası 1.,7., ve 15. gündeki bilirubin miktarları hastane arşiv sisteminden yararlanılarak kaydedildi. Tüm hastalarda safra yolu tıkanıklığına yol açan tümör çeşidi, tıkanıklı̆̆ın seviyesi ve karaciğer metastaz durumu kaydedildi. Çalışmaya sadece teknik olarak başarılı olgular ve 2 ay sonra bilirubin seviyesi $2 \mathrm{mg} / \mathrm{dl}$ 'nin altına düşmüş olgular alınd. Teknik başarı, kateterin ve stentin uygun yere yerleştirilebilmesi olarak kabul edildi. Perkütan biliyer drenaj işlemleri, konusunda 15 yıllık deneyimli girişimsel radyoloji uzmanı tarafindan yapılmıştı. PBD işleminde; önce giriş yeri ultrasonografi ile belirlenip giriş yeri sterilizasyonu ve lokal anestezi uygulamas1 sonras1 ultrasonografi ve skopi eşliğinde $21 \mathrm{G}$ iğne ile uygun periferik safra yoluna girip dilüye edilmiş non iyonik kontrast madde verilerek safra yolları görüntülenmiş daha sonra iğne içerisinden 0.018 klavuz tel ilerletilmiş ve bu tel üzerinden 4F koaksiyel dilatatör/k1lif sistemi (V stick vascular access set, Emergo Europe, Netherlands) safra yoluna ilerletilmiş ve hidrofilik kilavuz tel ile problemli safra segmenti geçilerek bağırsağa ulaşılmaya çalışılmış olup bazı hastalarda değişik çapta damar kılıfları ve bunların içerisinden ilerletilen değişik uçlu kateterlerden faydalanılmıştır. Problemli segment geçilip bağırsağa ulaşılması durumunda amplatz tel üzerinden $50 \mathrm{~cm} 7 \mathrm{~F}$ kalınlığında (Emergo Europe, Drainage Catheter, The Hague, Netherlands) çok delikli biliyer drenaj kateteri distal ucu barsakta, delikleri problemli segmentin hem proksimalinde hem de distalinde olacak şekilde yerleştirilmiştir. İşlem sonrası noniyonik kontrast madde verilerek kateter lokalizasyonu kontrol edilmiş ve kateter distal kesimi 
duodenum içerisinde uygun şekilde bırakılmıştır. İşlemlerden yaklaşık 3-7 gün sonra olgulara uygun çapta ve boyutta kendiliğinden genişleyen metalik stent (Wallstent, Boston Scientific, USA) implantasyonu yapılmıştır. İşlemlerde Siemens antis zee DSA cihazı (Siemens; Erlangen, Germany) cihazı ile Aplio 80 (Toshiba, Tokyo, Japan ) ultrasonografi cihazı kullanılmıştı.

\section{Istatistiksel analiz}

İstatiksel yöntemler SPSS (Statistical Package for Social Sciences) 17,0 bilgisayar programı kullanılarak yapıldı. Sayısal degiskenler ortalama \pm standart sapma $(\mathrm{Ort} \pm \mathrm{SS})$ olarak tanımland1. Kategorik degiskenler yüzde (\%) olarak tanımlandı. Bilirubin değişimleri ile diğer faktörler arasındaki ilişki pearson correlasyon testi ve bilirubin seviyesindeki düşüşü etkileyebilecek faktör analizi logistik regresyon testi ile yapild.

\section{Sonuçlar}

Çalışmada belirtilen tarihler arasında PBD yapılmış 102 olguya ait veriler incelendi. 17 olgu teknik başarı yetersiz olduğu için, 16 hasta ilk iki ayda ex olduğundan ve 29 hastaya ait planlanan günlerdeki bilirubin seviyelerine ulaşılamadığından çalışmadan çıkarıldı. Sonuç olarak işlem sonrası 2. ayda $2 \mathrm{mg} / \mathrm{dl}$ veya altında bilirubin seviyesine sahip 40 hasta çalışma grubunu oluşturdu. Hastaların 27 (\%67.5) tanesi erkek, 13 (\%32.5) tanesi bayand. Yaş ortalamaları 65 (34-85) idi. Hastaların $13 \quad(\% 32.5)$ tanesi pankreas malignitesi, $12(\% 30)$ tanesi kolanjioselüler karsinom, 10 (\%25) tanesi metastaz, $1(\% 0.25)$ tanesi safra kesesi kanseri, 4 (\%10) tanesi karaciğer kaynaklı maligniteydi. T1kanma seviyesi 24 olguda koledok seviyesinde, 16 olguda ise sağ, sol veya ortak hepatik kanalda izlendi. Olguların 27'sinde (\%52.9) işlem öncesinde karaciğer metastazı mevcuttu (tablo 1). Tüm hastalar incelendiğinde işlem öncesi bilirubin seviyesi ortalamas1; $13.0 \mathrm{mg} / \mathrm{dl}$, işlem sonras1 1. gün bilirubin seviyesi ortalamas 10.7 $\mathrm{mg} / \mathrm{dl}, 7$. gün bilirubin seviyesi ortalamas 18.02 $\mathrm{mg} / \mathrm{dl}$, 15. gün bilirubin seviyesi ortalamas 1 $5.29 \mathrm{mg} / \mathrm{dl}$ bulundu (grafik1). İşlem öncesi ortalama bilirubin seviyesine göre ortalama bilirubin miktarında 1 . gün $\% 17,7,7$. gün $\% 38,4$ ve 15 . gün $\% 59,4$ azalma izlendi. Bilirubin düşme miktarıyla drenaj öncesi bilirubin seviyesiyle arasında ilişki saptanırken $(p<0.001) \quad$ tıkanma seviyesi, tıkanma etiyolojisini oluşturan malignite çeşidi ve karaciğer metastazı olup olmamasının bilirubin seviyesindeki düşme hızı ile ilişkisi olmadığı saptand1 (tablo 2).

Tablo 1: Olguların ve lezyonların demografik özelliklerive işlem öncesi ortalama bilirubin seviyesi

\begin{tabular}{|c|c|}
\hline Cinsiyet (erkek)(\%) & $27(\% 67.5)$ \\
\hline Yaș (ortalama) & 65 \\
\hline $\begin{array}{l}\text { Primer Malignite } \\
\text { Pankreas (\%) } \\
\text { Kolanjioselüler CA(\%) } \\
\text { Metastaz(\%) } \\
\text { Safra kesesi tümörü(\%) } \\
\text { Primer Karaciğer tümörü(\%) }\end{array}$ & $\begin{array}{l}13(\% 32.5) \\
12(\% 30) \\
10(\% 25) \\
1(\% 0.25) \\
4(\% 10)\end{array}$ \\
\hline $\begin{array}{l}\text { Tikanma seviyesi } \\
\text { Koledok } \\
\text { Sağ,Sol veya Ortak hepatik } \\
\text { kanal }\end{array}$ & $\begin{array}{l}24 \\
16\end{array}$ \\
\hline Karaciğer metastazı (\%) & $27(\% 52.9)$ \\
\hline $\begin{array}{l}\text { İsslem öncesi ortalama bilirubin } \\
\text { seviyesi }\end{array}$ & $13.0 \mathrm{mg} / \mathrm{dl}$ \\
\hline
\end{tabular}

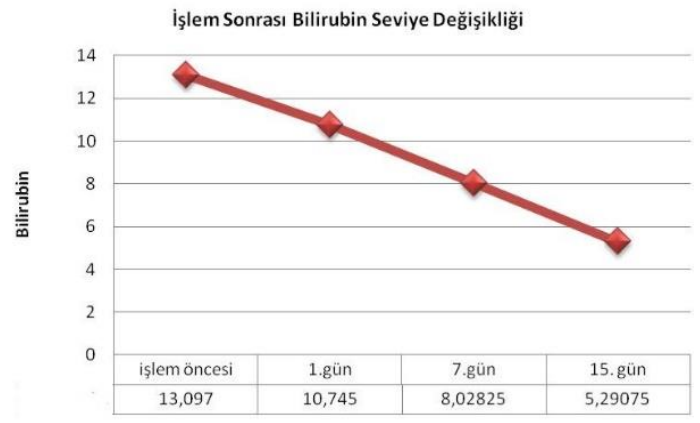

Grafik 1: İşlem öncesi ve işlem sonrası 1.,7. ve 15. günde bilirubin seviyesi ortalamasındaki değişiklikler

\section{Tartışma}

Safra yolu tıkanıklığı gastrointestinal, karaciğer ve safra yolu malignitelerinde sik görülen bir komplikasyon olarak karşımıza çıkmaktadır. Safra yolu tıkanıklığı sarılık ve kaşıntı gibi semptomlara yol açabileceği gibi kolanjit, malabsorbsiyon, ilerleyici karaciğer ve böbrek bozukluğuna da yol açabilir. Safra yolu tıkanıklığı olan olgularda serum bilirubin seviyeleri artmış olup yüksek bilirubin seviyeleri cerrahi, kemoterapi, radyoterapi ve radyofrekans ablasyon veya trans-arteriyal kemoembolizasyon gibi lokal tedaviler için kontrendikasyon oluşturmaktadır (1). Bilirubin seviyeleri ne kadar erken düşerse hastalar o kadar erken dönemde radikal antitümör tedavisi 
alabilirler. Safra yolu tıkanıklığında hepatik klirens azaldığından dolayı uygulanacak ilaç metabolizması değişebilir ve bu sebeple ilaca bağlı toksik etkiler ortaya çıkabilir (4-6). Kolon, mide ve pankreas kanseri kemoterapi protokolünde olan 5-Flourourasil uygulanabilmesi için bilirubin seviyesinin 5 $\mathrm{mg} / \mathrm{dl}$ nin altında olmas1 gerekmektedir (6). İrinotekan, serum bilirubini $2 \mathrm{mg} / \mathrm{dl}$ nin üstünde olanlarda kontrendikedir (3). Baz1 kemoterapötiklerde ise bilirubin seviyesine göre doz ayarlamaları yapılmaktadır. $\mathrm{Bu}$ hastalarda kemoterapinin etkinliği azalabilir. Migita ve ark (8), metastatik mide kanseri olgularında perkütan biliyer drenaj sonras1 kemoterapi uygulamasının hasta surveyini

Tablo 2: Perkütan biliyer drenaj ve stentleme sonrası ortalama bilirubin miktarındaki değişikliği etkileyebilecek faktörlerin 1., 7. ve 15. günlerdeki ortalama bilirubin miktarı ile ilişki analizi

\begin{tabular}{|c|c|c|c|}
\hline 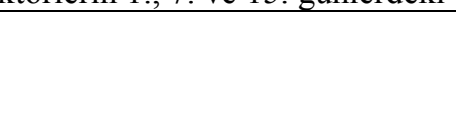 & $\begin{array}{l}\text { Ortalama bilirubin farkı } \\
\text { 1. Gün }\end{array}$ & $\begin{array}{c}\text { Ortalama bilirubin farkı } \\
\text { 7. Gün }\end{array}$ & $\begin{array}{c}\text { Ortalama bilirubin farkı } \\
\text { 15. Gün }\end{array}$ \\
\hline Tıkanıklık seviyesi & $p: 0.358$ & $p: 0.230$ & $p: 0.305$ \\
\hline Karaciğer Metastaz Durumu & $p: 0.924$ & $p: 0.911$ & $p: 0.821$ \\
\hline Malignite Çeşidi & $p: 0.952$ & $p: 0.721$ & $p: 0.230$ \\
\hline $\begin{array}{lll}\text { İ̀slem Öncesi } & \text { Bilirubin } \\
\text { seviyesi } & & \\
\end{array}$ & $p<0.001$ & $p<0.001$ & $p=0.001$ \\
\hline
\end{tabular}

Safra yolu tıkanıklıklarında endoskopik yaklaşım genellikle ilk tercih olmakla beraber özellikle yüksek yerleşimli tıkanıklarda endoskopik yaklaşım yetersiz kalmaktadır (7). Weston ve ark (11), endoskopik yöntemle plastik ve metal stent uygulayarak yaptıkları çalışmada, $2 \mathrm{mg} / \mathrm{dl}$ nin altı bilirubin seviyesine hastaların \%80 ininde, 2-6 haftada ulaş1labildiğini bildirmişlerdir. Thornton ve ark (3), ise PBD ile ulaşmak istedikleri bilirubin seviyesini $1 \mathrm{mg} / \mathrm{dl}$ olarak belirleyip bu seviyeye 100 günde ortalama olarak hastaların ancak \% 31'inin ulaştığını bildirmişlerdir. Lewy ve ark (7) , PBD ile istedikleri bilirubin seviyesini 2 $\mathrm{mg} / \mathrm{dl}$ ve $5 \mathrm{mg} / \mathrm{dl}$ olarak belirlemiş ve $5 \mathrm{mg} / \mathrm{dl}$ bilirubin seviyesine 30 günde hastaların $\% 62$ ' sinin, 60 günde ise \%84'ünün ulaştığını, 2 $\mathrm{mg} / \mathrm{dl}$ bilirubin seviyesine 30 günde hastaların $\% 37$ 'sinin 60 günde hastaların \%70'inin uzattığını bildirmişlerdir. Çok merkezli bir başka çalışmada ise kolanjiokarsinomlu olgularda perkütan biliyer drenajin mortalite oranını etkilemediği gösterilmiştir (9). Hatta pankreas başı tümörü olan olgularda PBD'nin cerrahi sonrası komplikasyonları artırdığını gösteren çalışma mevcut olup pankreas başı tümörü olanlarda PBD'nin gerekliliği tartış1maktadır (10). Zhang ve ark (1), ise 102 hastayı içeren çalışmalarında biliyer drenaj sonrası cerrahinin hasta surveyini uzattığını bildirmiştir. ulaşabildiğini bildirmişlerdir. Ayrıca yine bu çalışmada

istenilen bilirubin seviyelerine ulaşılmasında işlem öncesi bilirubin miktarının etkisi olmadığını sadece biliyer drenaj kateterinin boyutunun etkisinin olduğunu belirtmişlerdir. $\mathrm{Bu}$ çalışmanın aksine bilirubin seviyesinin istenilen düzeye inmesini işlem öncesi bilirubin miktarının etkilediğini belirten çalışmalar da mevcuttur (3,6). Zhang ve ark (1), çalışmalarında karaciğer metastazı olmasının düşük karaciğer rezervi ve ilerlemiş hastalık nedeniyle bilirubin seviyesindeki düşüşü kötü yönde etkilediğini bununla beraber hasta yaşı, yüksek bilirubin seviyesi ve obstrüksiyon seviyesi ile bilirubin seviyesindeki düşme arasında ilişki olmadığını göstermişlerdir. Bizim çalışmamızda bilirubin düşme miktarıyla drenaj öncesi bilirubin seviyesiyle arasında ilişki saptanırken tıkanma seviyesi, tıkanma 
etiyolojisini oluşturan malignite çeşidi ve karaciğer metastazı olup olmamasının bilirubin seviyesindeki düşme hızı ile ilişki saptanmadı. PBD sonrası erken dönemde bilirubin miktarını gösteren çalışma bulunmamakta olup bu çalışmada 2 ay sonra $2 \mathrm{mg} / \mathrm{dl}$ nin altında bilirubin seviyesine ulaşılan olgularda işlem öncesi ortalama bilirubin seviyesine göre ortalama bilirubin miktarında 1. gün \% 17,7, 7 . gün $\% 38,4$ ve 15 . gün $\% 59,4$ azalma izlendi. $\mathrm{Bu}$ çalışma başarılı PBD işlemi sonrası kemoterapi planlanan olgularda bilirubin miktarının işlem öncesi bilirubin miktarına bağlı olarak ilk iki haftada istenilen düzeye düşebileceğini ve hastaya erken dönemde kemoterapi başlanabileceğini göstermiştir. Ayrıca bilirubin seviyesinin erken dönemde düşebileceğinin bilinmesi ile cerrahi, radyofrekans ablasyon veya trans-arteriyal kemoembolizasyon gibi daha agresiv tedavi seçenekleride erken dönemde planlanabilir.

Malign olgularda PBD sonrası darlık bölgesine palyasyon amaçlı stent uygulaması önerilmektedir $(12,13)$. Stent uygulanmasinın yalnız PBD uygulanmasina göre patensisi daha fazla olduğu ve yalnız PBD uygulanmasında kateter değişimi sırasında kanser disseminasyonu olabileceğini bildiren çalışmalar olmuştur (13-15). Bizim çalışmamızdaki olguların hepsine PBD sonrası metalik stent uygulaması yapılmıştır. Biloma, safra yolları dışına olan safranın loküle koleksiyonu olup iyatrojenik veya malignitelere sekonder ortaya çıkabilir ve safra yoluna basıya neden olabilir (16). PBD ayrica malignitelere eşlik eden safra yoluna bası yapabilen bilomada da etkin bir yöntem olarak uygulanabilir (17).

Çalışmanın retrospektif dizaynı, az hasta sayısı içermesi, hastaların farklı malignitelere sahip olmas1, bilirubin seviyesinin $2 \mathrm{mg} / \mathrm{dl}$ 'nin altına inme süresinin tam olarak bilinmemesi ve 2 . ayda ki kontrolde $2 \mathrm{mg} / \mathrm{dl}$ üstünde bilirubin miktarına sahip olgu sayısının az olmasından dolayı bu olgularla karşılaştırma imkanımızın olmaması çalışmanın limitasyonlarını oluşturmaktadır

Sonuç olarak bu çalışma ile, malign safra yolu tıkanıklığı nedeniyle PBD-stentleme uygulanan, 2. ayda kemoterapi alabilecek düzeyde bilirubin seviyesine ulaşılabilen olguların bilirubin seviyelerinin işlem öncesi seviyelerine göre kısa dönemde belirgin düştüğü ve işlem öncesi bilirubin miktarının bilirubin düşüş hızını etkilediği gözlenmiştir.

\section{Referasnlar:}

1. Zhang GY, Li WT, Peng WJ, Li GD, He $\mathrm{XH}, \mathrm{Xu}$ LC. Clinical outcomes and prediction of survival following percutaneous biliary drainage for malignant obstructive jaundice. Oncol Lett. 2014;7:1185-90.

2. Hatzaras I, George N, Muscarella P, Melvin WS, Ellison EC, Bloomston M. Predictors of survival in periampullary cancers following pancreaticoduodenectomy. Ann Surg Oncol. 2010;17: 991-97.

3. Thornton RH, Ulrich R, Hsu M, Moskowitz C, Reidy-Lagunes D, Covey AM et al: Outcomes of patients undergoing percutaneous biliary drainage to reduce bilirubin for administration of chemotherapy. J Vasc Interv Radiol. 2012; 23: 89-95.

4. King PD. Hepatotoxicity of chemotherapy. Oncologist 2001; 6:162-76.

5. Floyd J, Mirza I, Sachs B, Perry MC. Hepatotoxicity of chemotherapy. Semin Oncol 2006;33:50-67.

6. Eklund JW, Trifilio S, Mulcahy MF. Chemotherapy dosing in the setting of liver dysfunction. Oncology 2005;19:1057-63.

7. Levy J.L, Sudheendra, D, Dagli M., Mondschein J.I, Stravropoulos S.W, Shlansky-Goldgerg R.D et al. Percutaneous biliary drainage effectively lowers serum bilirubin to permit chemotherapy treatment. Abdom Radiol 2016;41: 317-23.

8. Migita K, Watanabe A, Yoshioka T, Kinoshita $\mathrm{S}$ and Ohyama T: Clinical outcome of malignant biliary obstruction caused by metastatic gastric cancer. World J Surg 2009; 33:2396-2402.

9. Farges O, Regimbeau JM, Fuks D, Le Treut YP, Cherqui D, Bachellier $\mathrm{P}$, et al. Multicentre European study of preoperative biliary drainage for hilar cholangiocarcinoma. $\quad \mathrm{Br} \quad \mathrm{J} \quad$ Surg 2013;100:274-83.

10. van der Gaag NA, Rauws EAJ, van Eijck $\mathrm{CH}$, Bruno MJ, van der Harst E, Kubben FJ, et al. Preoperative biliary drainage for cancer of the head of the pancreas. New Engl J Med 2010; 362:129-37.

11. Weston BR, Ross WA, Wolff RA, Evans $\mathrm{D}$, Lee JE, Wang $\mathrm{X}$, et al. Rate of bilirubin 
regression after stenting in malignant biliary obstruction for the initiation of chemotherapy. Cancer 2008; 112:2417-23.

12. Lammer J, Hausegger KA, Flückiger F, Winkelbauer FW, Wildling R, Klein GE, et al. Common bile duct obstruction due to malignancy: treatment with plastic versus metal stents. Radiology. 1996 ;201:16772.

13. Dumonceau JM, Tringali A, Blero D, Devière J, Laugiers R, Heresbach D, et al.Biliary stenting: indications, choice of st ents and results: European Society of Gastr ointestinalEndoscopy (ESGE) clinical guid eline. Endoscopy.2012;44:277-98.

14. Mahgerefteh S, Hubert A, Klimov A, Bloom AI. Clinical impact of percutaneous transhepatic insertion of metal biliary endoprostheses for palliation of jaundice and facilitation of chemotherapy. Am J Clin Oncol 2015; 38:489-94.

15. Kwang MK, Park JW, Lee JK, Lee KH, Lee KT, Shim SG. A comparison of preoperative biliary drainage methods for perihilar cholangiocarcinoma:endoscopic versus percutaneous transhepatic biliary drainage. Gut Liver 2015; 9:791-99.

16. Christoforidis E, Vasiliadis K, Goulimaris I, Tsalis K, Kanellos I, Papachilea T, et al. A single center experience in minimally invasive treatment of postcholecystectomy bile leak, complicated with biloma formation. J Surg Res 2007; 141:171-5.

17. Arıbaş B, Arda K, Yakut F, Yılmaz K, Doğan K, Şahin G, Coşar Y. Malign bilier obstrüksiyonlarda ve eşlik eden bilomalarda perkütan bilier drenaj. Akademik Gastroenteroloji Dergisi 2010;9:16-21. 